\title{
Maintenance of Certification: What Everyone Needs to Know
}

\author{
Glenda G. Callender, $\mathrm{MD}^{1}$, Brian J. Kaplan, $\mathrm{MD}^{2}$, Richard L. White, $\mathrm{MD}^{3}$, David R. Brenin, $\mathrm{MD}^{4}$, \\ Anees B. Chagpar, MD, MSc, MA, MPH, MBA ${ }^{5}$, Kimberly M. Dalal, MD ${ }^{6}$, Marissa Howard-McNatt, MD $^{7}$, \\ James Howe, $\mathrm{MD}^{8}$, Joseph Kim, $\mathrm{MD}^{9}$, Scott H. Kurtzman, $\mathrm{MD}^{10}$, John C. Mansour, $\mathrm{MD}^{11}$, \\ Elizabeth A. Mittendorf, MD, PhD $^{12}$, John H. Stewart IV, MD $^{7}$, Larissa K. F. Temple, MD $^{13}$, \\ Patti Stella, BA, CCMEP ${ }^{14}$, Charmaine Cummings, PhD, RN, CCMEP ${ }^{14}$, \\ Sandra L. Wong, MD, MS ${ }^{15}$, and V. Suzanne Klimberg, $\mathrm{MD}^{16}$
}

${ }^{1}$ Yale Endocrine Surgery, Yale University School of Medicine, New Haven, CT; ${ }^{2}$ Virginia Commonwealth University, Richmond, VA; ${ }^{3}$ Carolinas Medical Center/Levine Cancer Institute, Charlotte, NC; ${ }^{4}$ University of Virginia, Charlottesville, VA; ${ }^{5}$ Yale Department of Surgery, Yale University School of Medicine, New Haven, CT; ${ }^{6}$ Palo Alto Medical Foundation, Burlingame, CA; ${ }^{7}$ Wake Forest University, Winston-Salem, NC; ${ }^{8}$ University of Iowa, Iowa City, IA; ${ }^{9}$ City of Hope National Medical Center, Monrovia, CA; ${ }^{10}$ Waterbury Hospital, Waterbury, CT; ${ }^{11}$ UT Southwestern Medical Center, Dallas, TX; ${ }^{12} \mathrm{MD}$ Anderson Cancer Center, Houston, TX; ${ }^{13}$ Memorial Sloan-Kettering Cancer Center, New York, NY; ${ }^{14}$ Society of Surgical Oncology, Rosemont, IL; ${ }^{15}$ University of Michigan, Ann Arbor, MI; ${ }^{16}$ University of Arkansas for Medical Sciences, Little Rock, AR

If you know the answer to the following question, read no further:

- For American Board of Surgery (ABS) Maintenance of Certification (MOC), how many hours of continuing medical education (CME) must you complete on average each year, and of these, how many CME hours must include self-assessment?
a. $20 \mathrm{CME}, 10$ self-assessment.
b. $30 \mathrm{CME}, 30$ self-assessment.
c. $30 \mathrm{CME}, 20$ self-assessment.
d. $10 \mathrm{CME}, 5$ self-assessment.
e. $15 \mathrm{CME}, 15$ self-assessment.

The answer is C. During a 3-year reporting cycle, the practicing surgeon must complete a minimum of $90 \mathrm{~h}$ of $\mathrm{CME}$, and 60 of these hours must include self-assessment, with $75 \%$ of self-assessment questions answered correctly. Thus, on average, the practicing surgeon needs to complete

(C) Society of Surgical Oncology 2015

First Received: 27 November 2014;

Published Online: 7 February 2015

G. G. Callender, MD

e-mail: glenda.callender@yale.edu
$30 \mathrm{~h}$ of CME per year, and 20 of these must include selfassessment. If you are unaware of these mandates, or if you know them but remain unsure about how to meet MOC requirements, read on. This editorial reviews the purpose of MOC, outlines current MOC requirements, and lists options to fulfill MOC available through the Society of Surgical Oncology (SSO) and its journal, Annals of Surgical Oncology (ASO).

MOC is an initiative developed by the American Board of Medical Specialties and its 24 member boards, including the ABS. The medical board initiative began in 1917 with the goal of setting standards for quality care. The ABS was formally chartered on July 19, 1937, by the leading surgical societies of that era to distinguish well-trained surgeons from others "to protect the public and improve the specialty." "Today there remains a recognized need for continued monitoring and promotion of quality in medicine, highlighted by the landmark Institute of Medicine report "To Err Is Human." 2 Board certification is the accepted gold standard for ensuring that a surgeon has acquired and is sustaining a certain level of knowledge, and MOC ensures that board certification remains a surgeondefined, publicly recognized standard of excellence. ${ }^{3}$ The ABS was the first board to institute recertification examinations, which provide a snapshot of a surgeon's knowledge every 10 years. However, MOC goes beyond 
traditional recertification; it is a continuous professional development program that provides and encourages ongoing learning, assessment and improvement throughout a surgeon's career. ${ }^{3}$ Every practicing surgeon taking a certifying or recertifying exam through the ABS after July 2005 has been enrolled in MOC; since recertifying exams occur every 10 years, all practicing surgeons will be enrolled in MOC by the end of 2015.

There are four components to MOC (Table 1$){ }^{3}$ MOC part 1 assures professional standing: the requirement to maintain a valid medical license and hospital privileges, and the obligation to provide the ABS with contact information for the chief of surgery and chair of credentials at your main institution. MOC part 2, implemented in 2012, requires demonstration of a commitment to lifelong learning and self-assessment. MOC part 3 is an assessment of cognitive expertise: the recertification exam that is required every 10 years. MOC part 4 is an evaluation of performance in practice and requires ongoing participation in an outcomes registry or quality assessment program. The

TABLE 1 Requirements for each part of MOC

\begin{tabular}{|c|c|}
\hline MOC part & ABS requirement \\
\hline $\begin{array}{l}\text { Part } 1 \text {-Professional } \\
\text { standing }\end{array}$ & $\begin{array}{l}\text { Valid, full and unrestricted medical } \\
\text { license (United States or Canada) } \\
\text { Hospital/surgical center privileges in } \\
\text { your specialty, if clinically active } \\
\text { Professional references: contact } \\
\text { information for the chief of surgery } \\
\text { and chair of credentials at institution } \\
\text { where most work is performed }\end{array}$ \\
\hline $\begin{array}{l}\text { Part 2-Lifelong learning } \\
\text { and self-assessment }\end{array}$ & $\begin{array}{l}\text { CME-Completion of } 90 \mathrm{~h} \text { of Category } \\
\text { I CME relevant to one's practice over } \\
\text { a 3-year MOC cycle. Category I CME } \\
\text { activities are formal educational } \\
\text { experiences such as seminars, grand } \\
\text { rounds, and skills courses } \\
\text { Self-assessment-At least } 60 \text { of the } 90 \\
\text { CME h must include self-assessment } \\
\text { A score of } 75 \% \text { or higher must be } \\
\text { achieved (no minimum number of } \\
\text { questions; repeated attempts allowed) } \\
\text { The ABS will waive } 60 \text { h of CME with } \\
\text { self-assessment for achieving ABS } \\
\text { certification or recertification. The } \\
\text { exam that enrolls you in MOC counts } \\
\text { toward your first 3-year cycle }\end{array}$ \\
\hline $\begin{array}{l}\text { Part } 3 \text {-Cognitive } \\
\text { expertise }\end{array}$ & $\begin{array}{l}\text { Successful completion of a secure MOC } \\
\text { (recertification) examination }\end{array}$ \\
\hline $\begin{array}{l}\text { Part } 4 \text {-Evaluation of } \\
\text { performance in practice }\end{array}$ & $\begin{array}{l}\text { Participation in local, regional or } \\
\text { national outcomes registry or quality } \\
\text { assessment program, either } \\
\text { individually or through your } \\
\text { institution }\end{array}$ \\
\hline
\end{tabular}

$M O C$ maintenance of certification, $A B S$ American Board of Surgery, $C M E$ continuing medical education reporting cycle for MOC is every 3 years. It is important to note that MOC requirements do not need to be repeated if a surgeon holds more than one certification through the ABS (e.g., general surgery and complex general surgical oncology). The remainder of this editorial will focus on MOC part 2 because it is less intuitive than the other parts of MOC.

MOC part 2 has two components: CME and selfassessment. Every 3 years, the practicing surgeon must report a minimum of $90 \mathrm{~h}$ of category I CME, of which at least $60 \mathrm{~h}$ must be self-assessment credit. Therefore, on average, $30 \mathrm{~h}$ of category I CME must be completed every year. Category I CME activities are formal educational experiences such as seminars, grand rounds, and skills courses relevant to one's practice. These activities are approved as CME by providers (such as hospitals or surgical societies) that are accredited through the Accreditation Council for Continuing Medical Education (ACCME). Of the $30 \mathrm{CME}$ hours, $20 \mathrm{~h}$ must include self-assessment, defined as a written or electronic question-and-answer exercise that assesses one's understanding of the material presented in the CME program. ${ }^{3}$ Completing the required evaluation of the CME activity at the end of the program is not the same thing as self-assessment. A score of $75 \%$ correct is required to receive the self-assessment credit, but there is no minimum number of questions required, and repeated attempts to answer the questions are allowed. To date, self-assessment activities do not require specific ABS approval, as long as they are contained within an approved CME activity. A timeline of the 3-year MOC reporting cycle as it pertains to CME and self-assessment is depicted in Table 2. Of note, an ABS certification or recertification exam counts for 60 self-assessment CME credits, sufficient for 3 years. An additional $30 \mathrm{~h}$ of regular category I CME (no self-assessment needed for regular CME) is still required during the 3-year period.

Most people have a tendency to procrastinate; thus, it is easy to leave MOC part 2 until the last minute. The 3-year MOC reporting cycle means that it is possible to end up needing to complete $90 \mathrm{~h}$ of CME, including $60 \mathrm{~h}$ of selfassessment, during the few days before a December 31 deadline or accept the penalty: being reported as "not meeting MOC requirements," facing additional requirements to reenter MOC, and being ineligible to certify or recertify in any ABS specialty until all MOC requirements are met. This extremely stressful situation is completely preventable. Many institutions offer CME with or without self-assessment credits for weekly grand rounds, tumor boards, and so on. Sign in, complete the self-assessment, be sure that you receive the credit, and keep the documentation. At annual meetings and conferences, take the time to claim CME credits, complete any available self-assessment, be sure that you receive the credit, and keep the 


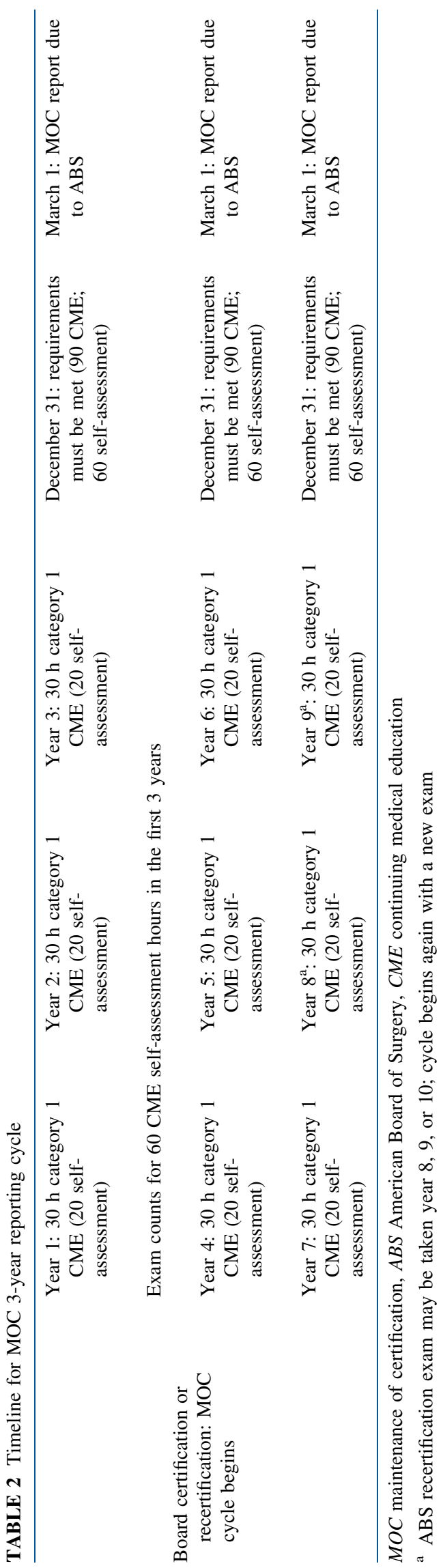

documentation. If your yearly numbers of CME or selfassessment credits are low, seek out additional options for self-assessment credit and keep the documentation. Then, at the end of a 3-year reporting cycle, just report what you have documented, and you are done. MOC part 2 is a straightforward requirement as long as you understand what needs to be done and develop habits that allow you to consistently work toward it.

In part because MOC part 2 requirements can seem so overwhelming, surgical societies and journals have begun to offer self-assessment CME credits, many of which can be uploaded directly to the American College of Surgeons (ACS) "My CME" Web site, facilitating documentation even further. Over the past few years, the SSO has focused extensively on supporting continuing education, with the creation of annual meeting courses and enduring materials that can be used to meet MOC requirements. ${ }^{4}$ Table 3 lists the options for obtaining self-assessment CME through the SSO and ASO. An easy way to obtain self-assessment CME is at the annual SSO meeting. At the Annual Cancer Symposium in March 2015, 12 sessions will offer selfassessment CME, for a total of 21.5 credits-which are sufficient self-assessment credits for an entire year. Annual meeting sessions offering self-assessment CME will be available online after the meeting for a year, so it is possible to obtain credits without actually attending the meeting, although there will be a fee for this activity. The Surgical Oncology Self-Assessment Program (SOSAP) is a casebased online learning tool modeled after the popular ACS Surgical Education and Self-Assessment Program (SESAP) but specifically designed for physicians seeking surgical oncology education. Up to 60 self-assessment credits are possible through SOSAP. The ASO offers one self-assessment credit per month for select articles from the journal and will soon launch an online module that includes 6 articles on the topic of neoadjuvant therapy in breast cancer, which will be worth up to 6 self-assessment credits. Finally, the SSO has partnered with the American Society of Clinical Oncology (ASCO) to offer 3 self-assessment modules that cover content presented each day of the January 2015 ASCO Gastrointestinal Cancers Symposium.

Surgeons who prefer to focus on a specific surgical oncology disease site for their self-assessment credits can usually do so. Most disease-site-specific surgical societies offer self-assessment credit at their annual meetings and are beginning to produce enduring materials that provide self-assessment credits. For example, the American Society of Breast Surgeons (ASBrS) offers the Breast Education Self-Assessment Program (BESAP), which provides self-assessment credits. The ASBrS also produces the Breast Handbook, a Web-based resource designed to help answer the BESAP questions. This type of initiative allows subspecialized surgeons to ensure that time spent on 
TABLE 3 Opportunities for self-assessment CME credits through the SSO and ASO

\begin{tabular}{|c|c|c|}
\hline Activity & Credits offered & Cost \\
\hline SSO Annual Cancer Symposium 2015 & $\begin{array}{l}12 \text { annual meeting sessions will provide } \\
21.5 \text { self-assessment credits }\end{array}$ & $\begin{array}{l}\text { Included with meeting registration fee; } \\
\text { same sessions will be available for a } \\
\text { fee to nonattendees later }\end{array}$ \\
\hline $\begin{array}{l}\text { Surgical Oncology Self-Assessment Program } \\
\text { (SOSAP) }\end{array}$ & 60 self-assessment credits & $\begin{array}{l}\text { SSO member } \$ 399 \\
\text { SSO member fellow } \$ 299 \\
\text { Nonmember } \$ 549 \\
\text { Nonmember fellow } \$ 329\end{array}$ \\
\hline ASO Journal CME/MOC & $\begin{array}{l}1 \text { article offered for } 1 \text { credit of self- } \\
\text { assessment per month }\end{array}$ & Currently free \\
\hline $\begin{array}{l}\text { ASO Journal Review Series-Neoadjuvant } \\
\text { Therapy in Breast Cancer }\end{array}$ & $\begin{array}{l}\text { Online module includes } 6 \text { articles worth } 6 \\
\text { self-assessment credits }\end{array}$ & Currently free \\
\hline ASCO 2015 Gastrointestinal cancers symposium & $\begin{array}{l}3 \text { modules will provide } 7.5 \text { self- } \\
\text { assessment credits }\end{array}$ & $\begin{array}{l}\text { SSO member } \$ 35 / \text { module } \\
\text { Nonmember } \$ 50 / \text { module }\end{array}$ \\
\hline
\end{tabular}

$C M E$ continuing medical education, SSO Society of Surgical Oncology, ASO Annals of Surgical Oncology

obtaining self-assessment credits is time spent in a manner that pertains to their actual practice. Over time, many more such opportunities will likely become available across a wide range of subspecialties.

In summary, MOC requirements may initially seem onerous. However, by understanding the requirements and devising a plan for ongoing participation in self-assessment activities, the MOC part 2 requirements are not difficult to fulfill. By taking advantage of opportunities offered year round, a December 31 deadline need not be feared, and the requirement will become more of an opportunity than a burden.

Conflict of interest The authors declare no conflict of interest.

\section{REFERENCES}

1. American Board of Surgery. ABS overview. http://www. absurgery.org/default.jsp?abouthome. Accessed 17 Nov 2014.

2. Kohn LT, Corrigan JM, Donaldson MS, editors. To err is human: building a safer health system. Washington, DC: National Academy Press, Institute of Medicine; 1999.

3. American Board of Surgery. Maintenance of certification (MOC): overview. http://absurgery.org/default.jsp?exam-moc. Accessed 17 Nov 2014.

4. Klimberg VS. Society of Surgical Oncology 2014 presidential address. Ann Surg Oncol. 2014;21:3699-707. 